\title{
MAPEAMENTO DA VEGETAÇÃO E USO DA TERRA PARA SUBSIDIAR A ANÁLISE DE VULNERABILIDADE SOCIAL E AMBIENTAL DE SANTOS - SP
}

\author{
Rodrigo de Jesus $^{(a)}$; Maria Isabel Catreghini de Freitas ${ }^{(b)}$ \\ ${ }^{(a)}$ Graduando do Curso de Geografia, bolsista PIBIC (2015-2016), Centro de Análise e Planejamento Ambiental \\ (CEAPLA)/Instituto de Geociências e Ciências Exatas, Universidade Estadual Paulista "Júlio de Mesquita \\ Filho", rodrigo.js94@gmail.com \\ (b) Professora Pesquisadora do Centro de Análise e Planejamento Ambiental (CEAPLA) e do Departamento \\ Planejamento Territorial e Geoprocessamento/ Instituto de Geociências e Ciências Exatas, Universidade \\ Estadual Paulista “Júlio de Mesquita Filho",ifreitas@rc.unesp.br
}

Eixo temático: GEOTECNOLOGIAS E MODELAGEM ESPACIAL EM GEOGRAFIA FÍSICA

\section{RESUMO}

\begin{abstract}
Esta pesquisa teve o objetivo de realizar o mapeamento da vegetação e do uso da terra do município de Santos SP, nosanos de 2003 e 2010 com suporte das técnicas de geoprocessamento. Os procedimentos metodológicos adotados, compreenderam a análise interpretativa das imagens aerofotogramétricas (ortofotos), vetorização das imagens para a extração das classes, utilização dos programas computacionais para a elaboração de mapas temáticos, com posterior verificação de campo visando a validação do mapeamento realizado. Como resultados, foram elaborados os mapas temáticos, em etapa posterior, foram utilizados para a análise das mudanças relativas à vegetação e à ocupação territorial. Observamos que as alterações mais expressivas no período decorreram da ampliação das instalações de edificações subnormais, ativididades portuarias e de mineração, que ocuparam principalmente as áreas de mangues e restingas. Tais mapeamentos foram fundamentais para subsidiar a análise de vulnerabilidade socioambiental do município de Santos SP, realizada em projeto em desenvolvimento no CEAPLA/Unesp.
\end{abstract}

Palavras-chaves: Uso da terra. Mapeamento. Vulnerabilidade social

\section{INTRODUÇÃO}

A modelagem de aspectos físicos e socioeconômicos constitui uma importante base para trabalhos que envolvem a prevenção, mitigação e o enfrentamento de manifestações de riscos, sejam eles naturais, sociais, tecnológicos ou mistos. No âmbito das geotecnologias, a cartografia e o sensoriamento remoto possuem potencial para evidenciar a ocorrência de eventos perigosos relacionados com o ser humano e com o ambiente, que permitam ações de planejamento, ordenamento do território ou mesmo de gestão de impactos decorrentes de desastres ou catástrofes.

Nessa situação, as geotecnologias, em especial o sensoriamento remoto e os sistemas de informação geográfica (SIG), são poderosas ferramentas para a modelagem de riscos naturais, sociais e tecnológicos e para o mapeamento da vulnerabilidade social e ambiental, que contribui para estabelecer os níveis de riscos a partir da combinação diferentes mapas temáticos, dentre os quais os devegetação, uso e ocupação das terras. 
As imagens de satélites e as fotografias aéreas obtidas pelos sensores remotos proporcionam uma visão sinóptica (de conjunto) e multitemporal (de dinâmica) de extensas áreas da superfície terrestre, que mostram os diferentes ambientes e suas transformações, destacando os impactos causados por fenômenos naturais e pela ação do homem através do uso e da ocupação do espaço (FLORENZANO, 2012). Em termos conceituais, o conhecimento das ameaças e vulnerabilidades está intimamente relacionado com a avaliação da suscetibilidade, ou seja, as condições presentes em um território que favorecem a ocorrência de fenômenos com potencial para gerar danos a um sistema. Concorda-se com a argumentação de que, numa aplicação ampla de sensoriamento remoto na elaboração dos mapas de suscetibilidade, um fator importante para o mapeamento é a cobertura do terreno (GREGORIO ET AL., 2015).

Nessa perspectiva, a análise de vulnerabilidade social e ambiental é resultado dos saberes das estruturas econômicas e sociais. Diante do aumento contínuo dos riscos urbano e da deterioração do meio ambiente, torna-se imprescindível o mapeamento da vegetação e do uso da terra para analisar o conjunto de infraestruturas territoriais que é basico na prevenção e mitigação dos desastres naturais.Nessa perspectiva surgiu esta pesquisa de teve como objetivo realizar o mapeamento e análise das transformações na vegetação e no uso da terra para a área do município de Santos SP em duas datas recentes: 2003 e 2010, analisar suas principais transformações, de forma a subsidiar estudos de vulnerabilidade. Deve-se salientar que esse mapeamento é parte do Projeto de Pesquisa em desenvolvimento no CEAPLA/Unesp denominado Metodologias em SIG para Estudos de Vulnerabilidades e Riscos Naturais: Estudos de caso no Estado de São Paulo, coordenado pela Profa. Dra. Maria Isabel Castreghini de Freitas.

\section{2 ÁREA DE ESTUDO}

Localizada no litoral paulista e a 72 quilômetros da capital (Latitude $23^{\circ} 56^{\prime} 27^{\prime}$ ' S e Longitude 4519'48" W), fazendo limites com os seguintes municípios: ao Norte, Santo André e Mogi das Cruzes; aoSul, Oceano Atlântico e Guarujá; à Leste, Bertioga e à Oeste, Cubatão e São Vicente. Sua área compreende aproximadamente $280 \mathrm{~km}^{2}$, com uma população de aproximadamente 419.400 habitantes e densidade demográfica de 1.494,26 (hab/km2) segundo o IBGE (2010).

Com as atividades econômicas predominantemente ligadas ao Porto de Santos - o maior da América Latina, com 13 quilômetros de extensão e por onde passa mais de um quarto de todas as cargas que entram e saem do Brasil, configurando-se como as principais fontes de riquezas do município, fazendo de Santos a cidade mais importante economicamente da Região Metropolitana da Baixada Santista e uma das mais ricas do país. (PREFEITURA DE SANTOS, 2016). 
XVII Simpósio Brasileiro

de Geografia Física Aplicada

I Congresso Nacional

de Geografia Física
OS DESAFIOS DA GEOGRAFIA FÍSICA NA FRONTEIRA DO CONHECIMENTO

Instituto de Geociências - Unicamp

Campinas - SP

28 de Junho à 02 de Julho de 2017

\section{MATERIAS E METODOLOGIA}

Com intuito de atingir os objetivos da pesquisa foram utilizados os seguintes materiais: ortofotografias retificadas coloridas de 2003,resolução espacial de 0,10m, na escala 1:5.000, com restituição equivalente à 1:1.000 para a área insular e na escala 1:30.000 e com restituição de 1:10.000 para a área continental. Para o mapa de 2010 utilizou-se ortofotografias retificadas na escala de 1:25.000 com resolução espacial de $1 \mathrm{~m}$. Em relação ao processo de mapeamento foram utilizados os programas computacionais: AutoCAD Map (Autodesk), versão 2015 licença estudantil e o SIG Arcgis 10.2, módulo ArcMap. Para o trabalho de campo foram utilizados GNSS (Global Navigation Satellite System) de navegação GPS Garmin Etrex 10.

A metodologia adotada para o desenvolvimento da presente pesquisa pode ser descrita resumidamente em seis etapas principais:

levantamento bibliográfico inicial que teve como objetivo a procura e a escolha de obras de apoio à consolidação do referencial teórico-metodológico utilizado para a compreensão das principais temáticas abordadas, norteando a questão da vulnerabilidade social e ambiental, assim como levantamendo de documentação cartográfica, para escolhas das imagens aerofotogramétricas;

análise interpretativa das imagens aerofotogramétricas (ortofotos) definindo 16 classes de uso: 1) Água, 2) Complexo viário, 3) Edificações convencionais, 4) Edificações isoladas convencionais, 5) Edificações subnormais, 6) Edificações isoladas subnormais, 7) Área portuária 8) Ferrovia, 10) Área de cultivo, 11) Mangue, 12) Restinga, 13) Gramíneas/solo exposto, 14) Mata, 15) Reflorestamento, 16) Outros usos (praças, cemitérios, áreas de lazer públicas e privadas);

vetorização manual das classes de vegetação e de uso da terra com a utilização do programa computacional AutoCAD Map 10.2. Durante a vetorização foram utilizadas imagens do Google Maps e do Google Earth, para verificar a algumas classes do mapeamento e dirimir dúvidas;

conversão dos arquivos DWG (formato do software AutoCAD Map 10.2) para os arquivos DXF (formato de exportação compatível com o Módulo ArcMap do ArcGIS) para a elaboração dos mapas temáticos;

trabalho de campo no município de Santos SP, no dia 28 de junho de 2016, na área insular no município e seu entorno, para verificar algumas áreas de mapeamento que geraram dúvidas, no qual ocorreu também o registro fotográfico das diferentes classes de vegetação e uso da terra. Durante o trabalho de campo registrou-se as coordenadas de pontos visitados com auxílio do GPS Garmin Etrex 10, o que facilitou a localização das áreas de uso e vegetação que geraram dúvidas durante a execução da pesquisa; 


\section{OS DESAFIOS DA GEOGRAFIA FÍSICA NA FRONTEIRA DO CONHECIMENTO \\ Instituto de Geociências - Unicamp \\ Campinas - SP \\ 28 de Junho à 02 de Julho de 2017}

reformulação dos mapas temáticos com base nas informações obtidas durante a execução do trabalho de campo. As análises das transformações da vegetação e uso da terra no período foram baseadas nas observações das distribuições espaciais dos locais com maiores suscetibilidades a vulnerabilidade social e ambiental.

\section{RESULTADOS}

Conforme os procedimentos metodológicos descritos para mapear a vegetação e o uso da terra de Santos SP nos anos de 2003 e 2010, são apresentados os seguintes resultados: produtos temáticos, que se referem aos mapas de vegetação e de uso da terra relativos ao período de 2003 e 2010, respectivamente, ilustrados nas Figuras 01 e 02.

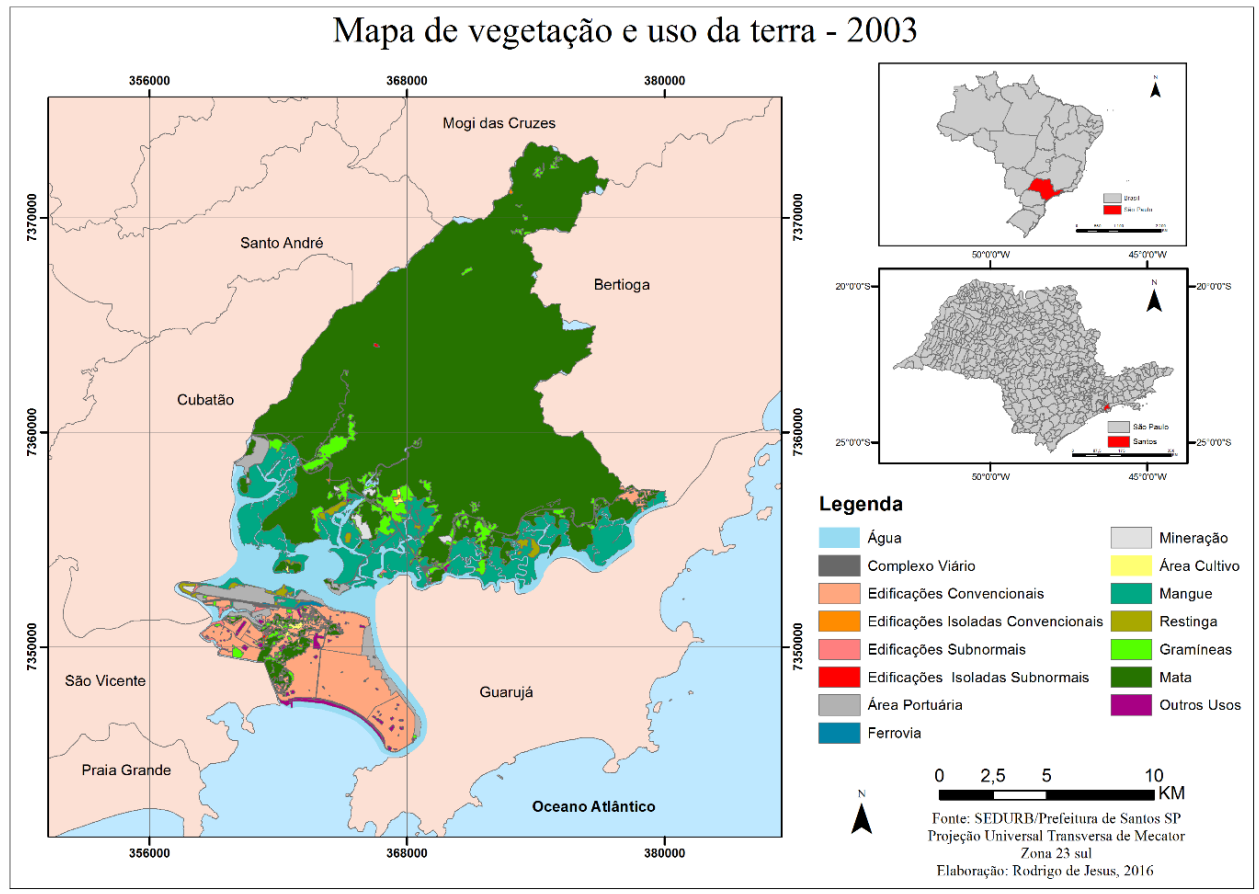

Figura 01 - Mapa de vegetação de uso da terra do município de Santos - SP no de 2003. 


\section{OS DESAFIOS DA GEOGRAFIA FÍSICA NA FRONTEIRA DO CONHECIMENTO Instituto de Geociências - Unicamp \\ Campinas - SP \\ 28 de Junho à 02 de Julho de 2017}

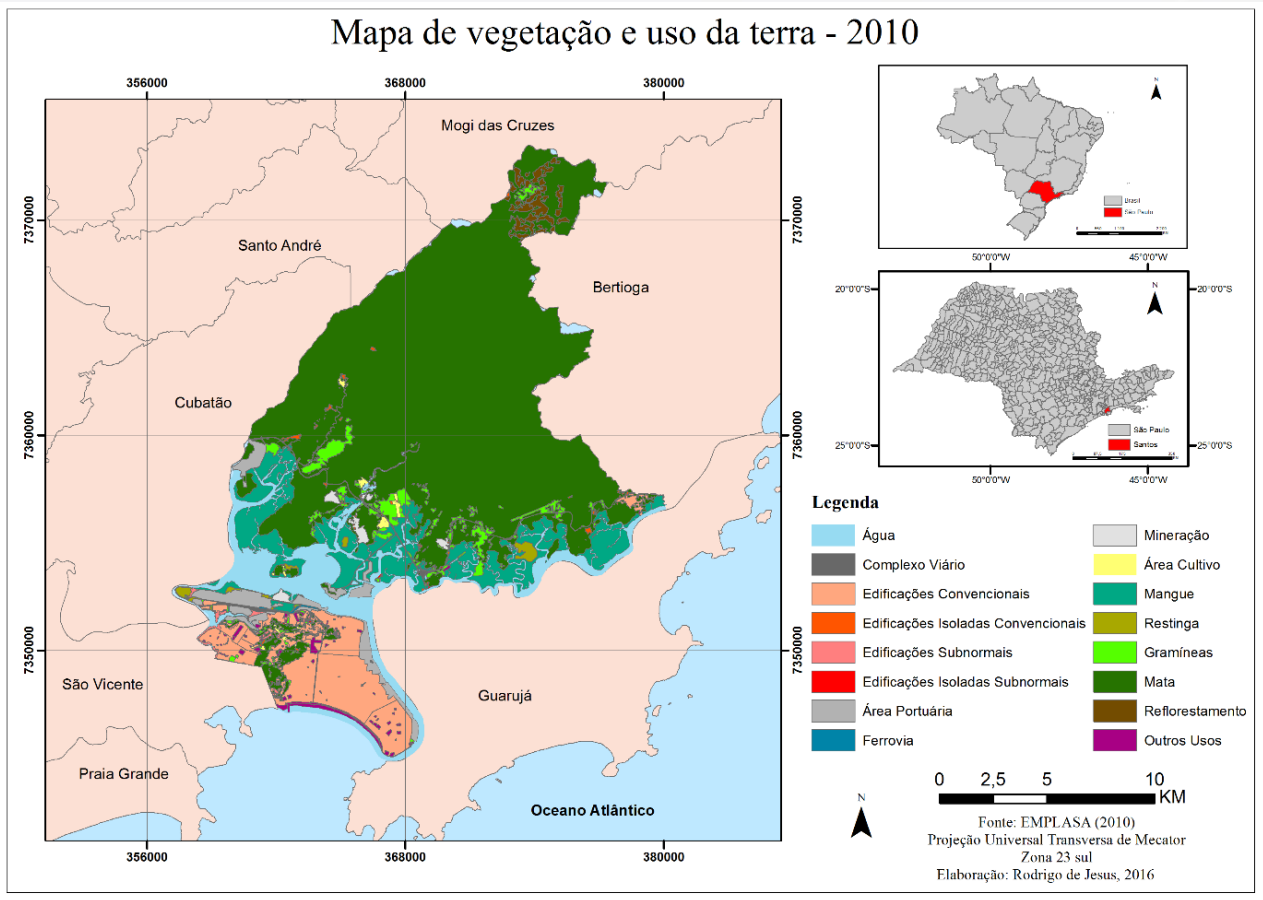

Figura 02 - Mapa de vegetação de uso da terra do município de Santos - SP no de 2010.

Ao analisar os dois mapas podemos evidenciar alterações, tais como: aumento das áreas de cultivo, e das áreas de atividades portuarias e de mineração. O aumento dessas áreas, ocasionou a diminuição das áreas de mangues e restingas. Esse fato é importante, pois nota-se um processo de alteração antrópica, que ocasiona um novo uso da terra totalmente diferente das relações que foram estabelecidas com o entorno anteriormente. Outra mudança que pode ser notada, é o surgimento da classe reflorestamento, evidenciando assim, que houve um processo de desmatamento no local.

Analisando os mapas, percebemos que existe uma quantidade expressiva de edificações subnormais, tanto na parte insular quanto na parte continental de Santos SP.Esses locais são complicados no ponto de vista da vulnerabilidade socioambiental, pois se encontram em áreas de encosta de morro, nos quais estão suscetíveis a deslizamentos ou em áreas de mangues e restingas, os quais, no ponto de vista ambiental e geomorfológico, são áreas inapropriadas para ocupação.

\section{CONSIDERAÇÕES FINAIS}

Podemos observar, com base no estudo, que o mapeamento da vegetação e do uso da terra permitiu evidenciar os locais com situações de exposição da população e do ambiente, principalmente por meio de classe de vegetação, como restinga e mangue que foram substituídos por edificações. Também, puderam-se evidenciar as ocorrências de alteração das classes por atividades de cultivo, mineração e atividades portuárias, e, identificar os locais com aglomerados de edificações subnormais. 
A metodologia adotada se mostrou consistente e permitiu o uso das Geotecnologias para a identificação dos locais com maiores concentrações da população vulnerável. O trabalho de campo confirmou alterações mais importantes na área de estudo, previamente interpretadas por meio de imagens de sensoriamento remoto.

Diante disso, pôde-se concluir que os mapas temáticos de vegetação e do uso da terra para o período, são produtos básicos em estudos de vulnerabilidades, pois permitiram espacializar os fenômenos para melhor identificação as transformações ambientais ao longo do tempo.

Tais produtos e procedimentos podem contribuir para futuras ações de planejamento, principalmente aquelas que auxiliem no controle e na prevenção de ocupações impróprias em locais de ecossistemas frágeis e importantes para o equilíbrio ambiental.

\section{REFERÊNCIAS}

FLORENZANO, Tereza Gallotti. Imagens de satélites para estudos ambientais. São Paulo: Oficina de Textos, 2002.

GREGORIO, L. M. Di et al. Sensoriamento remoto para gestão (riscos) de desastres naturais. In: SAUSEN, T. M. Sensoriamento remoto para desastres. $1^{\mathrm{a}}$ edição. São Paulo: Oficina de Textos, 2015. Pagina: 43 a 67.

INSTITUTO BRASILEIRO DE GEOGRAFIA E ESTATÍSTICA (IBGE). Cidades@. Disponível em: $<$ http://cidades.ibge.gov.br/xtras/temas.php?lang=\&codmun=354850\&idtema=16\&search=saopaulo|santos|sintese-das-informacoes> Acesso em: 25 novembro, 2016.

PREFEITURA DE SANTOS. Disponível em: <http://www.santos.sp.gov.br/conheca-santos $>$. Acesso em: 25 novembro, 2016. 